Di $\mathrm{WANG}^{1 *}$ and Dazhuang $\mathrm{LI}^{2}$

\title{
THE COGNITION OF THE SPATIAL ART FORMS OF TOURIST VILLAGES BASED ON ECOLOGICAL ENGINEERING AND SUSTAINABLE DEVELOPMENT
}

\begin{abstract}
With the development of information technology, the improvement of production processes and lifestyles, and the transformation of commercial economic models, the traditional agricultural industry cannot meet the increasing material and cultural needs of villagers. Therefore, the development of traditional tourist villages has transformed into being based on ecological engineering and sustainable development. The starting point of the existence of such tourist villages will be the protection and development of traditional villages. At the same time, the village space is the material carrier for the development of rural tourism, and the construction of a spatial form that is compatible with the tourism resource utilization model can effectively promote the development of rural tourism. Based on SWOT analysis, this article carefully analyses and summarises the domestic research on the sustainable development of tourist villages. The results show that such sustainable development effectively avoids the excessive development of resource elements during rural construction, which can lead to waste, and promotes the optimal use of resources. Since rural tourism has taken a sustainable development path, the average annual compound growth rate has reached as high as $31.2 \%$, which is considered very rapid growth. Tourist operating income has reached more than $30 \%$. It is expected that the national rural tourism income in 2021 will exceed 10,000 trillion yuan. Tourism villages will continue to consider ecological engineering and sustainable development as the starting point for promoting the development of rural tourism in China, popularising consumption, standardising services, diversifying benefits, and making products unique.
\end{abstract}

Keywords: ecological engineering, sustainable development, tourist village, spatial art form, SWOT analysis

\section{Introduction}

\section{Background and significance}

According to the "Thirteenth Five-Year" Tourism Development Plan, 2020 is the last year of the plan. The total number of people involved in China's tourism industry will reach 6.7 billion, with a total tourism investment of 2 trillion yuan and total industry revenue of 7 trillion yuan. China will become the world's largest tourism country and the largest domestic tourist market in the world. The tourism industry is known as the "smoke-free industry" and "sunrise industry" and has become one of the largest industries with the greatest growth potential in the world. However, with its development, this industry will subsequently face problems that have a negative impact on the ecological environment and

\footnotetext{
${ }^{1}$ College of Art and Design, Xijing University, Xi'an 710000, Shaanxi, China, ORCID: 0000-0002-5180-1487

${ }^{2}$ Faculty of Humanities and Arts, Macau University of Science and Technology, Macau 999078, China, email: dali311@163.com, ORCID: 0000-0002-7311-6106

*Corresponding author: amissddllqq@163.com
} 
social culture of the tourist destination [1]. For example, the blind development of tourism resources, the excessive expansion of the tourism infrastructure, and the extensive management of tourist attractions have severely affected the sustainable development of tourism [2]. The application of a sustainable development model has led to the governments and organizations of various countries beginning to prioritise the sustainable development of the tourism industry. Given the rapid growth and developments of science, technology and economy, traditional villages must quickly adapt and integrate these developments, always following a path of sustainable development based on ecological engineering to better preserve the original appearance of villages and to maintain the village for a long time. The fading charm of tourist villages continuously attracts more tourists and promotes the economic development of such villages [3].

\section{Domestic research}

An important way to realise the sustainable development of tourism, according to a consensus reached by domestic scholars, is ecotourism. From the perspective of the consumer experience, Zhao Limin used the ASEB (Activity, Setting, Experience, Benefit) analysis framework to analyse the sustainable development of ecotourism and proposed countermeasures based on this framework. Shi Dan explored the development direction of China's ecotourism based on professional theory [4]. An increasing number of scholars have said that the most basic and important way to better realise the sustainable development of tourism is to perform carrying capacity management. According to the theory of tourism capacity, Li Tianyuan proposed that controlling tourism carrying capacity is a key issue involved in the sustainable development of tourism destinations. Sun Muyou and Wang Yefeng studied and calculated the resource carrying capacity, ecological environment carrying capacity and psychological carrying capacity of residents in Qinhuangdao. The Third Plenary Session of the Eighteenth Central Committee made a series of important resolutions and developments, such as "retaining the original village features and formulating traditional village protection and development plans." The objective product of the combination of the concept of sustainable development and the practice of rural tourism is called ecotourism [5].

Rural tourism is a new concept, and there are always difficulties and problems inherent in new concepts. Through certain special policies and services, the growth rate of rural tourism can be effectively increased. Providing low-interest and relatively fast credit services can usually solve the financing problems of rural tourism development; regular management and financial training can improve the management level of tourism operators; competitive health, environmental and service incentives can promote tourism operators to improve these aspects; and an open information technology platform can help tourism operators promote Internet+.

\section{Foreign research}

Research on rural tourism in foreign developed countries began more than a century ago, and many achievements worthy of attention and reference have been made since then $[6,7]$. In the research on rural tourism development, foreign researchers have paid attention to the characteristics of rural areas. In the current era, with the increasingly serious environmental crisis, increasing attention has been paid to sustainable tourism villages. Foreign scholars often use factual case studies and discussions to prove the sustainable development of rural tourism. They mainly study the future development of tourism 
villages, the local government's implementation of relevant policies in the village, and the impact of rapidly developing information technology on sustainable tourism villages $[8,9]$. Murphy believes that the local residents of tourist villages must participate in the development of these villages and understand the development trend, including the development and repair of local resources in the village, planning and research for future development, and project implementation [10,11]. These aspects are not only relevant for developers. The benefits of resident participation are more related to their living comfort and the in-depth implementation of sustainable development models.

\section{Innovation}

Many scholars have studied the concept of sustainable development from different angles. At the same time, the sustainable development of rural tourism is also an issue to which many scholars and experts have paid attention. In contrast, the greatest innovations discussed in this article are as follows:

(1) This article considers ecological engineering the entry point, which is in line with the strategic layout of the entry of ecological culture into the national "five in one" strategy. Therefore, the construction of ecological culture is in line with this policy framework.

(2) On the basis of summarising and using relevant research results at home and abroad, based on ecological engineering and sustainable development, theoretical research on the sustainable development of rural tourism in China has been conducted, and the research foundation of China's rural tourism ecological culture theory has certain theoretical significance for promoting its scientific development.

(3) Starting from the theory of ecology and sustainable development, this article discusses the main source of ecological problems in terms of development based on research papers on ecological engineering and the sustainable development of rural tourism at home and abroad. The concept of China's rural tourism and ecological ethics has clarified the research direction and influence of the sustainable development of rural tourism.

(4) This article focuses on the current situation of rural settlement space. According to development law, the factors that affect the development of rural settlements are classified from both internal and external perspectives. This article focuses on how to develop rural tourism resources and spatial characteristics under the guidance of natural and human resources.

\section{Research methods}

\section{Ecological engineering}

The tourism industry has the characteristics of a great economy, great ecology, great artistic features, high connectivity, high growth and high sociality. Therefore, the development of any tourism industry is a very complex system engineering problem. To be precise, such development becomes an ecosystem project [12].

Although the tourism industry has many important characteristics, as a specific tourism project, the most important events in its systematic process are high degrees of completion, transparency and sensitivity. In the course of practice, tourism projects mainly include many important aspects, such as feasibility studies, strategic layouts, design and planning, development and construction, operation management and renewal development. In its 
various stages, every small matter or its connection is always multidimensional, complex, and cohesive and is often in a constantly evolving internal and external environment. According to preliminary experience, such a comprehensive, open and sensitive large-scale complex system project must be based on the main characteristics of overall integration, the building system and expansion time. Moreover, appropriate action should be taken and responded to well $[13,14]$. Especially in the planning stage of strategic layout, design and planning, we must fully understand the following characteristics of the tourism ecosystem in constructing its overall design [15].

\section{Sustainable development}

Sustainable tourism is the eternal theme of tourism development. The theory of sustainable development first appeared in the field of ecology, and people first paid attention to ecological sustainability $[16,17]$. With the intensification of the contradiction between humans and nature, the concept of sustainable development has gradually expanded from ecology to a wide range of fields such as society, the economy, culture, science and technology, and organizational management. In addition to the rapid development of tourism, tourism activities can also have an impact on the purpose of tourism, and people's awareness of environmental protection has thus gradually increased. The fragility and sensitivity of tourism determines its close relationship with "sustainable development". Especially in the late 1980s, when sustainable development was introduced into the concept of management and development, an inseparable relationship between "tourism" and "sustainable development" was established. The unanimous recognition of "sustainable development" in academia has gradually become a lifelong research topic in the tourism industry [18].

Low-carbon tourism is a new type of tourism with the features of low energy consumption and low pollution. This is a tourism method that integrates green and ecological tourism and promotes the coordinated development of tourism and environmental protection for all aspects. Of course, low-carbon tourism is a new way to develop tourism in the macroenvironment of a low-carbon economy, and an increasing number of tourists agree with this concept.

Regarding the premise of not affecting ecological sustainability, the sustainable development of tourism can not only meet the tourism expectations of contemporary people but will also not damage the requirements of future generations due to excessive development and environmental damage; at the same time, tourism must be guaranteed. The interests of operators, tourists and community residents promote healthy and long-term sustainable tourism development. The mutually beneficial coexistence and common development of the relationship between humans and nature and among humans must be ensured, and the sustainable development of nature, the economy and society must be realised [19].

\section{Tourist villages}

Tourist villages are an important way for the public to pursue a better life. They play a more obvious role in increasing people's happiness and building a harmonious society. With the proposal and subsequent progress of the agricultural revitalization strategy of the 19th National Congress of the Communist Party of China, rural tourism has entered a path of rapid growth. In recent years, rural tourism in many areas has developed into daily nostalgia and leisure activities for urban residents [20], which not only enrich the types of 
tourism products but also provide significant opportunities and resource reorganization for the transformation and upgrading of local tourism [21]. Based on the good economic, social and ecological functions of the tourism industry, as well as its close connection with the countryside, rural tourism has become widely known as a new channel that can save a country's declining countryside, especially by helping poor and rich individuals maintain social harmony and stability. Moreover, hope is increased. Based on the central role of rural tourism in the process of rural revitalization, the sustainable development of rural tourism has become an urgent problem to be solved.

Rural tourism has unique advantages. It can adapt to the growing consumer demand for nearby short-distance entertainment and urban residents' vacations. It shows strong vitality, beyond that of general tourism, and plays an increasingly important role in improving the quality of urban life and the rural population and promoting poverty reduction in poor areas. In addition, the construction of new countrysides is improving, and the rural tourism market is developing rapidly. Its essence is to provide tourists with authentic rural, natural and cultural ecological landscapes and agricultural cultural experiences, including communication between people and nature, between people and history, and among people, which is consistent with ecological culture. Rural tourism is not just a pure consumption behaviour. Through active participation in rural tourism activities, it can also enhance the harmony between humans and nature and guide people in developing a tourism mindset that loves nature, protects ecology and cares for others. Tourist villages are rich in resources, and the development trend of the spatial form of tourist villages with different resource structures is different. Research on the spatial form of rural tourism settlements under the new normal is conducive to the sustainable development of rural areas and provides a good reference for the planning and design of modern urban and rural spaces.

\section{Space art form}

The concept of "spatial form" is widely used in areas such as geography, architecture, and urban and rural planning. This is a concept with broad contributions and expanded scope. As the name implies, "form" has two meanings; shape means form and style, usually refers to appearance composed of surfaces or lines other than objects or graphics [22]. State refers to both the "behaviour" and "mental state" contained in the object, and it is the inner psychological response. Form is a combination of appearance and psychology. The renewal of the functional structure of rural settlements will inevitably lead to changes in the natural spatial structure. The spontaneous and unorganised construction of space in rural settlements has caused scattered spatial planning, the loss of rural space and the destruction of ecological space, which all hinder the development of rural tourism.

"Shape" refers to the key feature of the objective existence of things, which is usually interpreted as the outline, shape or form of things. The appearance and shape of things are described by the objective characteristics of "shape" with its main characteristics. "State" is an inherent characteristic of things. A change in "shape" generates external attraction, indicating the internal "state" of the "shape". Form refers to the change in and reflection of the external characteristics of the shape in the human brain. This change and reflection come from people's understanding of surrounding things and is affected by many factors, such as social culture, science and technology, and artistic concepts. The description of form is the overall description of the unity of form and spirit. Therefore, art form is the form and state of art, as well as the characteristic of art [23]. This feature develops with changes in various factors, such as space, time, nation, social culture, and the artistic 
significance of art. The relationship between the spatial form system and the resource allocation system is shown in Figure 1.

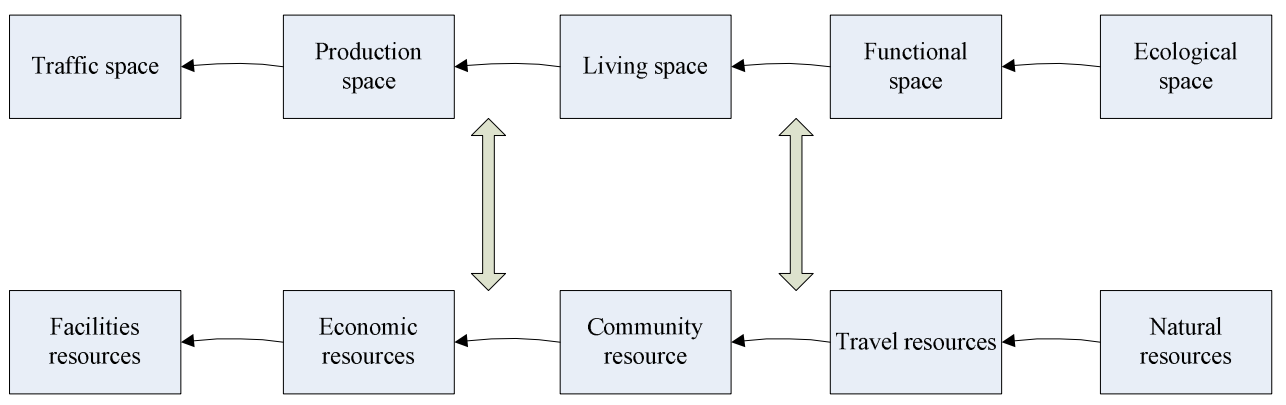

Fig. 1. Schematic diagram of the coordination and coupling relationship between the spatial form system and the resource allocation system

The development of production is an important driving force behind the development of rural spatial forms. First, in the study of the changes in rural areas in the last century, it can be seen that village area has shown that it has adapted to the development of production in different periods and includes the entire land of the village. The size of this area is as small as the house, which inadvertently covers the initial state of production. Second, the production and development of villages determines the income level of villagers, which indirectly determines the construction mode of villages, the continuous changes in the construction area and construction quality.

\section{Bearing capacity}

When the development of a tourist destination reaches a certain degree of acceptable change and exceeds its carrying capacity, the supportive attitude of community residents in the initial stage of tourism development will be reversed; that is, the development of tourism in any place has certain limitations. Peak growth beyond social capacity will have a negative impact. Scholar Wang Lingna analysed the corresponding framework of the sustainable development of rural tourism and pointed out that to achieve sustainable development, tourist destinations must consider the basis of prohibiting serious or irreversible environmental damage and ensure that tourists' behaviour can be ensured for a long time. Tourism should be developed, and some tourists should be allowed to develop tourism activities, referring to the technical term "environmental transportation capacity". To realise the sustainable development of rural tourism, the development of tourism and the number of tourists must not exceed the carrying capacity of the environment. The calculation of environmental carrying capacity and the carrying capacity of ecology, humanities, environment, etc. can only be adjusted according to the critical value of the weakest link [24]. Methods for achieving sustainable ecological and energy-saving buildings include ecological graphic design, landscape design, the use of building materials, reduction in wood use, and the sustainable use of energy. 


\section{SWOT analysis}

SWOT analysis refers to the situation analysis based on the internal and external competition environment and competitive conditions, which is to list the main internal advantages, disadvantages and external opportunities and threats closely related to the research object through investigation, and arrange them in a matrix format, and then use the thought of system analysis to match various factors together to analyze, and draw a series of corresponding conclusions from it. Based on an analysis of the internal and external competitive environment and situation of competitive conditions, the main internal advantages, disadvantages, external opportunities and threats closely related to the research objects are identified and then classified into a matrix. The objective of system analysis is to analyse various factors, combine them, and draw a series of corresponding conclusions. These conclusions usually have the special nature of decision making. Using this method, it is possible to conduct comprehensive, systematic and accurate research on the location of the research object to formulate corresponding development strategies, plans and countermeasures based on the research results.

\section{Experiment}

\section{Test subject}

From the perspective of the rural holiday tourism market supply, although the development of rural holiday tourism in China is not yet mature, its development momentum is strong, rural holiday tourism products have begun to form, and a large number of rural holiday bases have emerged. In 2011, Land A became the first national rural holiday tourism experimental area, marking the start of the construction of the national rural tourism area. This area belongs to the northeastern part of the city, between $117^{\circ} 21^{\prime} 56.6^{\prime \prime}$ and $118^{\circ} 12^{\prime} 13.7^{\prime \prime}$ east longitude and $29^{\circ} 01^{\prime} 43.3^{\prime \prime}$ and $29^{\circ} 34^{\prime} 39.3^{\prime \prime}$ north latitude, with a total area of 2967 square kilometres.

\section{Experimental design}

In recent years, this local area has better implemented sustainable development and committed to moving towards green growth, paying more attention to environmental protection and, at the same time, using local resources to optimise its spatial form to better manage carrying capacity to achieve maximum environmental protection. Sustainable development not only improves the living environment of local residents but also brings about various ecological benefits. To better carry out sustainable development and improve the level of environmental protection, a reasonable and effective evaluation index system must be established to determine whether it meets the requirements of sustainable development.

To comprehensively and objectively assess whether tourist villages are well equipped with sustainable development strategies, there are several principles that must be followed when defining rating indicators: (1) the principle of combining stability and dynamics; (2) science, completeness, and the principle of combination; (3) the principle of feasibility; and (4) the principle of combining quantitative and qualitative aspects.

\section{Steps for evaluating the Index System}

(1) First, effective factors and other factors are selected based on the above principles. 
(2) Second, when determining the correct factor weights, the relevant AHP (Analytic Hierarchy Process) method can be used.

(3) Then, the main steps of the fuzzy comprehensive evaluation method are followed step by step to obtain a complete evaluation score.

(4) Finally, a set of indicator systems and a comprehensive evaluation indicator for the sustainable development of agricultural tourism must be established to clarify environmental sustainability, resource sustainability, sustainable development and social sustainable development.

\section{Determination of evaluation Index Weight}

(1) An existing paired dependent variable analysis comparison matrix

$$
A=\left(a_{i j}\right) n \cdot n(i, j=1,2,3 \ldots, n)
$$

is constructed, generally using 1-9 and their reciprocals. The scaling method is used to better judge the value of the matrix elements.

(2) The weight of each judgement matrix is calculated, and the geometric mean $\bar{w}_{i}$ of all elements in each row of the judgement matrix is identified, namely:

$$
\bar{w}_{i}=\left(\prod_{j=1}^{n} a_{i j}\right)^{\frac{1}{n}} i=1,2 \ldots, n
$$

In the formula, $n$ is the order of the judgement matrix.

(3) Consistency check: when calculating the consistency index, assuming that matrix $A$ is completely compatible, it satisfies $\lambda_{\max }$; otherwise, it satisfies $\lambda_{\max }>n$. Therefore, whether $\lambda_{\max }-n$ is satisfied is generally used to judge the degree of compatibility deviation. Assuming that the compatibility index is $C I$ :

$$
\begin{aligned}
C I & =\frac{\lambda_{\max }-n}{n-1} \\
\lambda_{\max } & =\frac{1}{n} \sum_{i=1}^{n} \frac{(\mathrm{Aw})_{i}}{w_{i}}
\end{aligned}
$$

The order of the matrix is $n$.

\section{Experimental results}

With the rapid development of the domestic tourism industry, the local tourism industry has adopted a series of sustainable measures based on ecological engineering and sustainable development and summarised and put forward the development principles and models of the tourism village space, which not only greatly accelerated the local economy but also increased the income of residents, achieving a double harvest of economic benefits. The results show that the region's GDP (Gross Domestic Product) is 13.15 billion yuan, an increase of $8.6 \%$ over the last year. Among them, the value added of the primary industry is 1.038 billion yuan, an increase of $3.3 \%$; that of the secondary industry is 3.004 billion yuan, an increase of $8.4 \%$; and that of the tertiary industry is 9.108 billion yuan, an increase of $9.3 \%$. 


\section{SWOT analysis and the spatial shape influence of sustainable development on tourist villages}

This paper analyses local sustainable tourism based on SWOT analysis, explores its relationship with the spatial form of tourist villages through resources, the environment and other aspects, clarifies the factors of the spatial development of tourist villages, and analyses the development of local ecotourism to better realise the local sustainable development of tourism to drive economic growth.

\section{Research analysis}

In the context of the great development of tourism, the local tourism industry has also achieved rapid development, which has promoted the development of the local economy, increased fiscal revenue, and achieved the harmonious development of economic and social benefits. The development of local tourism has directly promoted the development of the local economy. Local tourist reception soared from 3.4 million in 2009 to 21 million in 2018, and comprehensive income also increased from 100 million yuan in 2009 to 160 million in 2018. Value added with tourism as the core accounts for $53.9 \%$ of GDP, and tourism has become the leading industry in the local economy. In addition, the tourism industry has driven the rapid development of the local accommodation and catering industry and provided a large number of employment opportunities for local residents, as shown in Figure 2.

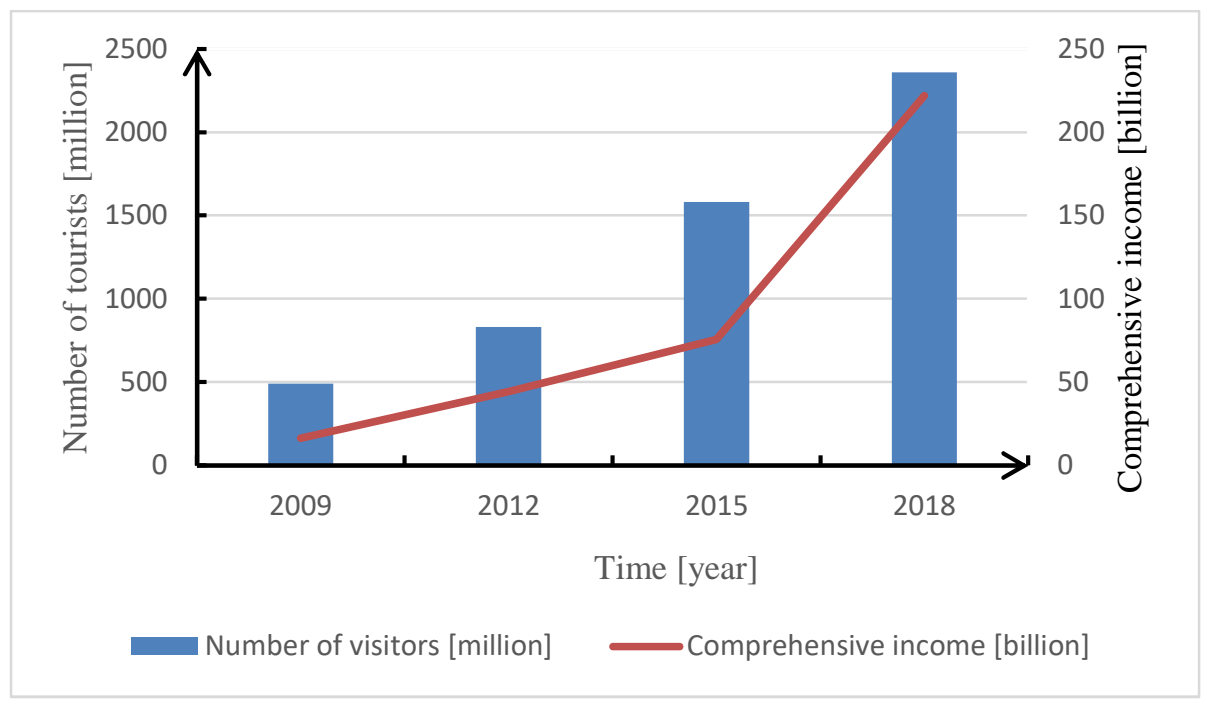

Fig. 2. Number of tourists and comprehensive income in 2009-2018

In 2018, the region's GDP was 13.15 billion yuan, an increase of $8.6 \%$ over 2017 . The value added of the primary industry was 1.038 billion yuan, an increase of $3.3 \%$; that of the secondary industry was 3.004 billion yuan, an increase of $8.4 \%$; and that of the tertiary industry was 9.108 billion yuan, an increase of $9.3 \%$, as shown in Figure 3. 


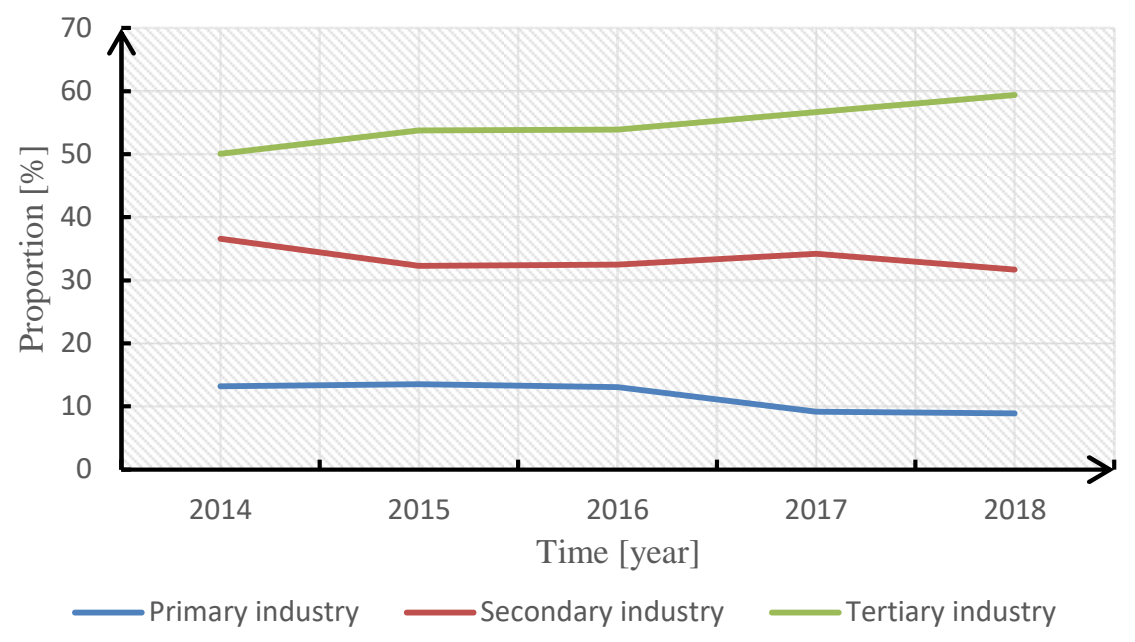

Fig. 3. The proportion of the three industrial structures in regional GDP

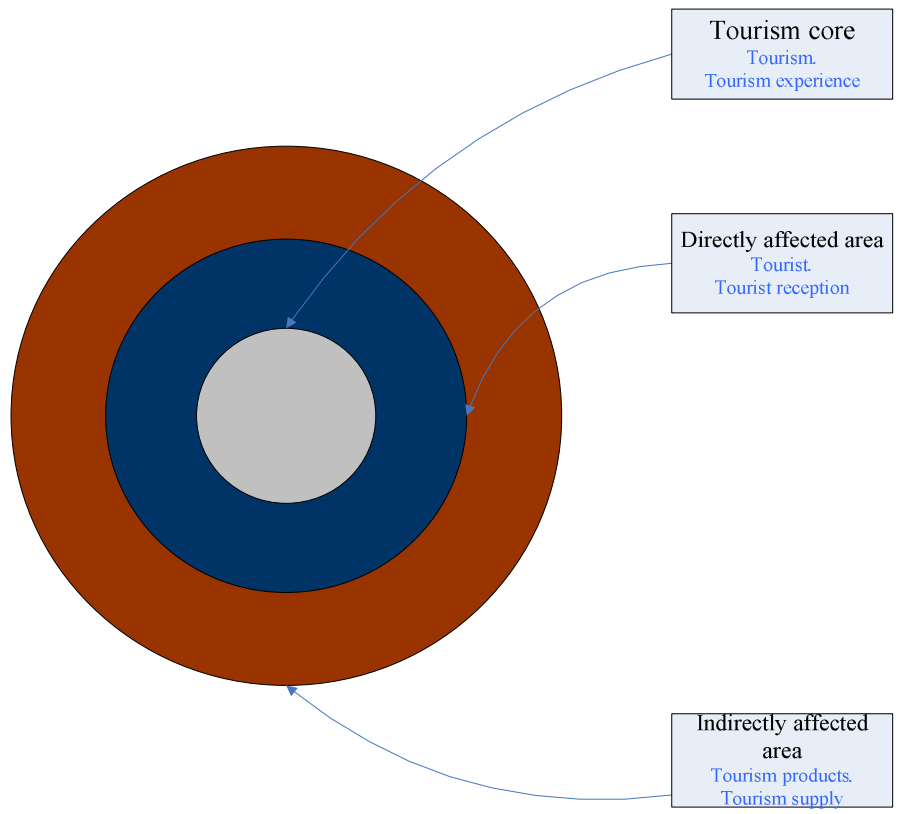

Fig. 4. Spatial distribution pattern

A good ecological space has had a positive impact on rural tourism, and the overall local distribution presents the characteristics of small-scale organic scattering. At the same time, artificial space based on sustainable development occupies a large part of the local area. This not only ensures its relative independence and independence but is also affected 
by resource conflicts and the close relationship between them. The organic distribution of a village matches its spatial topography. Tourist destinations are distributed in a circle, centred around the main villages depending on the tourist type. The rural tourism industry has developed from the core to the peripheral model, and rural land use patterns and lifestyles show regular changes, as shown in Figure 4.

In terms of the perception of a positive economic impact from tourism development, young residents aged 20-40 years have a stronger perception of this positive impact than do those in other age groups, while middle-aged and elderly residents over 60 years have a greater perception of this positive economic impact. For other age groups, the average difference in perception is between 0.6 and 0.7 , but the perception of the positive impact of tourism development on the social culture and environment of middle-aged and elderly residents over 60 years is not much different from that of other age groups. In terms of the perception of a negative economic impact of tourism development, residents between 40-60 years have the strongest perception, and residents under 20 years have the weakest perception of the negative effects of tourism, with a perception gap of 0.52 . In terms of attitudes towards the development of tourism, the average values of residents of all age groups are not much different, especially regarding the perception that "the benefits of tourism development outweigh the disadvantages" being very strong and the average value being above 4.2 , indicating that residents of all age groups see the development of tourism as being positive, as shown in Figure 5 .

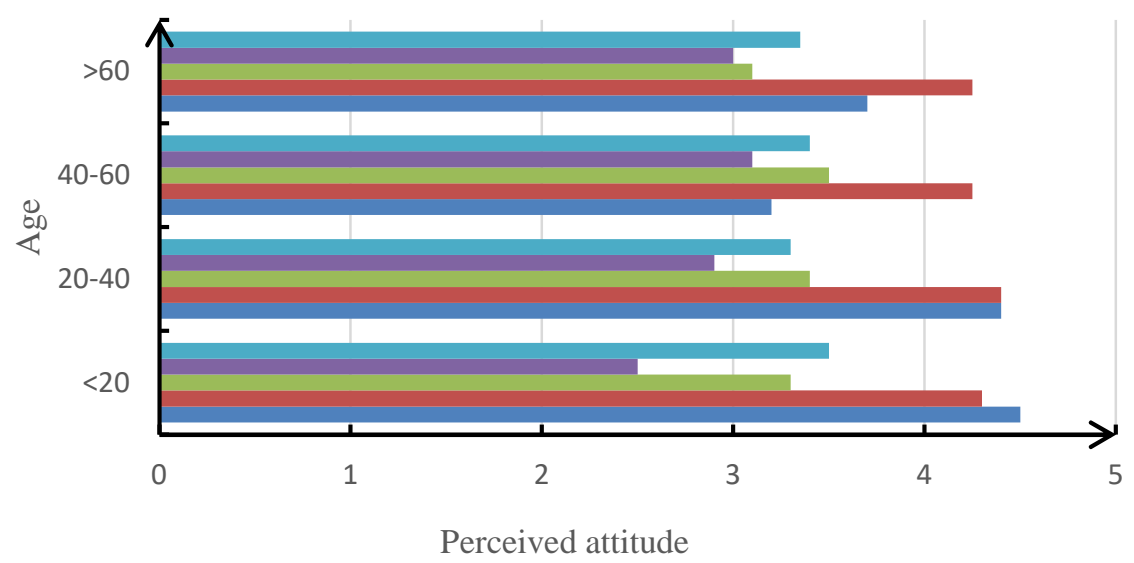

Attitude

Negative environment $\square$ Negative economy

Positive environment Economic positive

Fig. 5. Perceptions and attitudes of residents of different ages towards tourism impact

To maximise the associated benefits, many businesses seldom consider social and environmental benefits, neglecting sustainable development, which can lead to the emergence of many types of pollution. At the same time, businesses will also move to existing buildings to attract more tourists, leading to the emergence of problems related to 
building reconstruction and house demolition. Therefore, this research conducted a survey on relevant personnel, as shown in Figure 6.

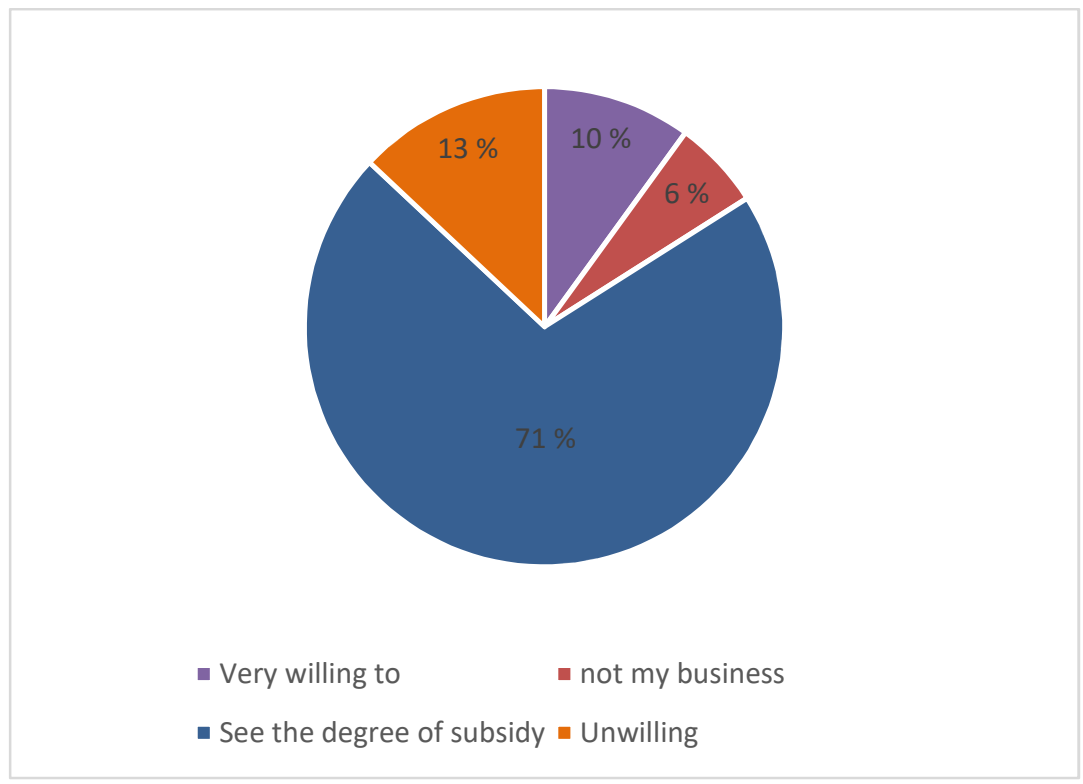

Fig. 6. Poll results regarding whether to rebuild

Based on the actual situation, the questionnaire used is designed to include economic, social, cultural and environmental impacts, and a Likert scale is used to measure impact indicators, as shown in Table 1.

Perception of the economic impact of tourism

\begin{tabular}{|c|c|c|c|}
\hline Survey item & $\begin{array}{c}\text { Neutral rate } \\
{[\%]}\end{array}$ & $\begin{array}{c}\text { Approval rate } \\
\text { [\%] }\end{array}$ & $\begin{array}{c}\text { Opposition rate } \\
{[\%]}\end{array}$ \\
\hline $\begin{array}{c}\text { Promoted economic } \\
\text { development }\end{array}$ & 4.42 & 88.01 & 5.34 \\
\hline Increased residents' income & 4.36 & 85.29 & 4.01 \\
\hline Improved living standards & 4.40 & 89.35 & 4.01 \\
\hline Caused prices to rise & 3.69 & 59.99 & 13.35 \\
\hline $\begin{array}{c}\text { Led to polarization between } \\
\text { rich and poor individuals }\end{array}$ & 3.31 & 48.65 & 37.99 \\
\hline
\end{tabular}

\section{Analysis of advantages and disadvantages}

(1) Advantages. Natural ecotourism resources are integrated with human ecotourism resources. The local forest coverage rate is high. There are 1 national forest park, 1 provincial nature reserve, and 188 nature reserves below (and including) the county level. The mountains are beautiful, and the air is pure. Because of this, this local area is one of three ecological forestry counties, and the only ecological forestry county in our city, is one of the ecotourism counties that have been approved by the state. Abundant 
natural ecological resources constitute a complete and large natural ecosystem, covering an area of $2,947,151 \mathrm{~km}^{2}$. The peaks in tourism are competitive and continuous, with unique tourism resources.

(2) Disadvantages. Incomplete infrastructure: a complete infrastructure is an important type of support for the development of rural tourism. In recent years, the rapid increase in tourism demand has contradicted its lagging infrastructure construction, which has hindered the expansion of the local tourism industry to a certain extent. Single product development form: as the local government lacks detailed planning and guidance on tourism resource development, the development of local tourism resources is always conducted in tourism and farmhouse projects. The form of tourism product development is single, and the degree of product development is not deep enough to truly satisfy the diverse needs of tourists and is not conducive to the sustainable development of local rural tourism. Management and professional talent are scarce; some managers fail to correctly interpret national policy requirements or pay insufficient attention to rural tourism, and it is difficult to guide and lead local residents to do a good job in terms of rural tourism development due to the lack of a comprehensive talent introduction and training mechanism and severe constraints on the sustainable development of local rural tourism.

\section{Future development}

With the continuous improvement of China's GDP and residents' income and consumption levels and the shortening of urban and rural space distances, primary rural tourism products can no longer meet the needs of the public, and products are gradually becoming more refined. High-end farmhouses, folk villages, pastoral farms, and farm technology products such as gardens, ancient villages, and rural resorts are endlessly emerging. In the next few years, rural tourism will develop into a new major force in the tourism industry. Through the development of rural tourism, a rural tourism consumer city market will be launched to promote the popularization of consumption and product characteristics in rural tourism in China. Service standardization will benefit diversified development.

With the country's vigorous development of the rural leisure tourism industry, rural e-commerce has been further developed, and a batch of liveable and business-friendly villages and towns have been cultivated. In addition, smart development is gradually being applied to the rural tourism industry. In the future, actions such as "tourism+" and "Internet+" will promote the development of leisure tourism, tourism e-commerce, and urban tourism and expand the value chain of the rural tourism industry.

The difference in resource utilization patterns is reflected in the spatial pattern of rural settlements having different spatial morphological characteristics. Tourist villages, dominated by natural resources, show different spatial development trends according to the location relationship between villages and natural scenic spots. Rural settlements should break through the environmental constraints between natural space and the overall space of the village in spatial development, open the spatial environment of the village to the natural environment, and build an open network space system between nature and the village so that rural settlements can effectively use the surrounding natural landscape resources. 


\section{Conclusion}

The sustainable development of rural tourism aims to promote rural economic and social development. At the same time, it also focuses on maintaining the integrity and sustainability of the rural natural and human ecological environment. This is a concrete manifestation of ecological culture. For today's tourist villages, following the path of sustainable development based on ecological engineering is an inevitable choice and a major trend in all tourism industries. Rural ecotourism develops sustainable resources, the economy, society and the environment in a coordinated way. If tourist villages want to develop quickly and sustainably, then they must take local resources and the environment as the starting point and be consistent with the local economy, culture and social ethics to better realise the coordinated development of tourist villages and the natural environment and maximise the potential for a sustainable development path.

Rural tourism settlements present different resource development trends due to their different resources and environment. The rural tourism industry based on natural resource development requires both natural resources and human resources, which provide complementary advantages. The development of the rural tourism industry based on human resources involves many types of agricultural human resources in a wide range of areas. In the development process, the human resource data of rural residential areas must be explored in depth, integrated and used as a whole.

The conversion of specific areas into low-carbon tourism areas not only conforms to the current growth trend of tourism but also attracts more tourists with sustainable development characteristics. Taking a local area as an example, this article establishes a sustainable development model through in-depth research on the development of tourism and proposes a specific development strategy that can provide references for China's low-carbon tourism research and other tourism destinations. At the same time, China's rural ecotourism is currently facing serious environmental problems, overexploitation of resources, imperfect management modes, and excessive profitability of developers. These problems can all be dealt with well after stably embarking on a sustainable development path.

\section{Acknowledgements}

This work was supported by 2017 Xijing University School-level Scientific Research Fund Project: Research on Space Village Art Creation Based on Nostalgic Memory Taking Yuanjia Village as an Example (No. XJ170209).

\section{References}

[1] Lin W. Monitoring and protection of forest ecological tourism resources by dynamic monitoring system. Ecol Chem Eng S. 2019;26(1):189-97. DOI: 10.1515/eces-2019-0018.

[2] Noe E, Alre HF. Sustainable agriculture issues explained by differentiation and structural coupling using social systems analysis. Agron Sust Develop. 2014;35(1):133-44. DOI: 10.1007/s13593-014-0243-4.

[3] Amelung D, Funke J. Laypeople's risky decisions in the climate change context: climate engineering as a risk-defusing strategy? Human Ecological Risk Asses Int J. 2015;21(2):533-59. DOI: 10.1080/10807039.2014.932203.

[4] Grafius DR, Corstanje R, Warren PH, Evans KL, Hancock S, Harris JA. The impact of land use/land cover scale on modelling urban ecosystem services. Landscape Ecol. 2016;31(7):1509-22. DOI: 10.1007/s10980-015-0337-7. 
[5] Small TW, Schoech SJ. Sex differences in the long-term repeatability of the acute stress response in long-lived, free-living Florida scrub-jays (aphelocoma coerulescens). J Comparative Physiol B. 2015;185(1):119-33. DOI: 10.1007/s00360-014-0866-4.

[6] Wyborn C, Yung L, Murphy D, Williams DR. Situating adaptation: How governance challenges and perceptions of uncertainty influence adaptation in the rocky mountains. Regional Environ Change. 2015;15(4):669-82. DOI: 10.1007/s10113-014-0663-3.

[7] Sirota M, Valuš L, Tourangeau FV. Now you Bayes, now you don't: effects of set-problem and frequency-format mental representations on statistical reasoning. Psychonomic Bulletin Rev. 2015;22(5):1-9. DOI: $10.3758 / \mathrm{s} 13423-015-0810-\mathrm{y}$.

[8] Manley EJ, Orr SW, Cheng T. A heuristic model of bounded route choice in urban areas. Transportation Res Part C: Emerging Technologies. 2015;56:195-209. DOI: 10.1016/j.trc.2015.03.020.

[9] Sardar Z. Postnormal times revisited. Futures. 2015;67:26-39. DOI: 10.1016/j.futures.2015.02.003.

[10] Rhodes RE, Quinlan A. Predictors of physical activity change among adults using observational designs. Sports Medicine. 2015;45(3):423-41. DOI: 10.1007/s40279-014-0275-6.

[11] Galaz V, Osterblom H, Bodin O, Crona B. Global networks and global change-induced tipping points. Int Environ Agreements Politics Law Economics. 2016;16(2):1-33. DOI: 10.1007/s10784-014-9253-6.

[12] Kersh N. Rethinking the learning space at work and beyond: The achievement of agency across the boundaries of work-related spaces and environments. Int Rev Education. 2015;61(6):835-51. DOI: $10.1007 / \mathrm{s} 11159-015-9529-2$.

[13] Mcneese N, Cooke NJ, Fedele M, Gray R. Perspectives on team cognition and team sports - ScienceDirect. Sport Exercise Psychol Res. 2016;123-41. DOI: 10.1016/B978-0-12-803634-1.00006-6.

[14] Tskhay KO, Rule NO. People automatically extract infants' sex from faces. J Nonverbal Behavior. 2016;40(4):247-54. DOI: 10.1007/s10919-016-0235-y.

[15] Cruz C, Espedido F, Abeledo RB. Shaping minds to action: an evaluation of the environmental influences of primary school students in an urbanizing community. Environ Development Sust. 2015;17(3):641-52. DOI: 10.1007/s10668-014-9551-8.

[16] Jha AP, Morrison AB, Parker SC, Stanley EA. Practice is protective: Mindfulness training promotes cognitive resilience in high-stress cohorts. Mindfulness. 2017;8(1):1-13. DOI: 10.1007/s12671-015-0465-9.

[17] Liu WZ, Lu HP. Analysis on difficult situations and strategies of constructing ecological civilization of enterprises. Ecol Economy. 2016;12(1):52-7. DOI: CNKI:SUN:STJY.0.2016-01-006.

[18] Boon HJ. Climate change ignorance: an unacceptable legacy. Australian Educational Researcher. 2015;42(4):405-27. DOI: 10.1007/s13384-014-0156-x.

[19] Manczarski P, Lelicinska SK, Anna RK. Assessment of the efficiency of biological treatment of gases from municipal waste processing. Ecol Chem Eng S. 2019;26(4):687-96. DOI: 10.1515/eces-2019-0049.

[20] Ambrose CE, Gross AM. Interpreting sexual dating encounters: Social information processing differences in men and women. J Family Violence. 2016;31(3):361-70. DOI: 10.1007/s10896-015-9757-z.

[21] Bodur HO, Duval KM, Grohmann B. Will you purchase environmentally friendly products? Using prediction requests to increase choice of sustainable products. J Business Ethics. 2015;129(1):59-75. DOI: 10.1007/s10551-014-2143-6.

[22] Michael S. The boundaries of art and social space in Rome: The caged bird and other art forms by Frederick Jones. Am J Philology. 2018;139(1):161-5. DOI: 10.1353/ajp.2018.0007.

[23] Ernst D, Esche C, Erbsloh U. The art museum as lab to re-calibrate values towards sustainable development. J Cleaner Production. 2016;135(1):1446-60. DOI: 10.1016/j.jclepro.2016.06.196.

[24] Vidya T. Art forms in nature. Resonance. 2018;23(11):1283-311. DOI: 10.1007/s12045-018-0736-6. 